Article

\title{
Analysis of the Multi-Steps Package (MSP) for Series-Connected SiC-MOSFETs
}

\author{
Luciano F. S. Alves $\mathbb{D}$, Pierre Lefranc, Pierre-Olivier Jeannin, Benoit Sarrazin and \\ Jean-Christophe Crebier*
}

Electrical Power Engineering, University Grenoble Alpes, CNRS, Grenoble INP, G2Elab, F-38000 Grenoble, France; luciano-francisco.sousa-alves@g2elab.grenoble-inp.fr (L.F.S.A.); pierre.lefranc@g2elab.grenoble-inp.fr (P.L.); pierre-olivier.jeannin@g2elab.grenoble-inp.fr (P.-O.J.); benoit.sarrazin@g2elab.grenoble-inp.fr (B.S.)

* Correspondence: jean-christophe.crebier@g2elab.grenoble-inp.fr

Received: 10 July 2020; Accepted: 18 August 2020; Published: 19 August 2020

\begin{abstract}
In this paper, a multi-step packaging (MSP) concept for series-connected SiC-MOSFETs is analyzed. The parasitic capacitance generated by the dielectric isolation of each device in the stack has a significant impact on the dynamic behavior of $\mathrm{SiC}$ devices, which impacts the voltage-sharing performances. The study performed in this work reveals that the parasitic capacitance network introduced by the classical planar packaging unbalances the voltage across the series-connected SiC-MOSFETs. Therefore, a new drain-source parasitic capacitance network configuration provided by the MSP is proposed in order to improve the voltage balancing across the series-connected devices. The concept is introduced and analyzed thanks to equivalent models and time domain simulations. To verify the analysis, the voltage sharing between four series-connected $1.2 \mathrm{kV} \mathrm{SiC} \mathrm{MOSFETs} \mathrm{is} \mathrm{tested}$ in a double pulse test setup. The experimental results confirm that the MSP has a better performance than the classical one in terms of voltage sharing. Furthermore, the proposed investigation shows that the MSP increases the middle point $d v / d t$ of the switching cell. Sensitive analysis and thermal management considerations are also discussed in order to clarify the MSP limitations and indicate the ways to optimize the MSP from a thermal point of view.
\end{abstract}

Keywords: series connection; SiC-MOSFETs; packaging

\section{Introduction}

Silicon (Si) power devices have dominated the world of power electronics in recent years, and they have proven to be efficient in a wide range of applications. However, high-power, high-frequency, and high-temperature applications require more than Si can deliver. Wide band-gap (WBG) devices such as silicon carbide ( $\mathrm{SiC}$ ) MOSFETs have been intensively researched and developed for power electronics applications due to the substantial advantages their inherent material properties could realize at device level, such as high breakdown voltage, high operating electric field, high operating temperature, high switching frequency, and low losses [1-3].

Commercial SiC-MOSFETs $(1.7 \mathrm{kV}, 3.3 \mathrm{kV}$ and $10 \mathrm{kV})$ have attracted great attention, especially for medium-high voltage applications under higher switching frequencies $[4,5]$. To further increase the device blocking voltage level, high and medium voltage switching devices by connecting SiC-MOSFETs in series connection is desired since series-connected devices are an effective way to increase the blocking voltage capabilities of the SiC-based switches to answer application constraints above $1.7 \mathrm{kV}$. Furthermore, according to [6], using two or more medium-voltage semiconductors in series features better on-resistance and higher current density than using a single higher-voltage device. However, 
the main problem related to the series association of power devices is the unequal voltage sharing among them that, if not mitigated, can result in device failure.

The voltage balancing across the series-connected devices is mainly caused by the tolerance in device parameters, package/layout parasitic components, and gate signal timing delays [7-9]. Careful selection of power semiconductor devices, which have parameters with low spread and synchronizing gate-drive signals, are helpful in reducing voltages unbalance across the power devices. In addition to this, snubber circuits, active gate drive circuits, voltage clamping techniques [7-11], and new concepts of packaging as described in $[12,13]$ have also been reported as interesting contributions in an attempt to reduce or even remove the voltage unbalance among the series-connected power devices.

Considering the high switching speed behavior of SiC-MOSFETs, intrinsic device parasitic and external parasitic capacitances have a strong impact on the dynamic voltage-sharing performance. As demonstrated in [13], one of the most important parasitic capacitances contributing to unequal dynamic voltage sharing among series-connected devices is the parasitic capacitance introduced by the packaging $\left(C_{p a c}\right)$, which is located between the drain terminal of the device and the common baseplate of the power module or common heatsink.

Parasitic capacitances introduced by the gate driver circuitry can also impact the voltage-sharing performance [3,14]. However, in order to focus on the impact of the packaging/layout on the dynamic voltage sharing without having to consider the impact of the gate drivers and theirs supplies, their influence is neglected in this paper. In the experiments, batteries are used to supply the gate drivers, and optical fibers are used to transfer the gate signals. A circuit is implemented in each gate driver to adjust the delay time among them and to tune the switching transitions. In such a way, and if enough care is carried out for the implementation, gate driver circuitry impacts on the voltage unbalancing can be neglected.

The paper is organized as follows: In Section 2, the traditional packaging is presented, and an analytical modeling is proposed. The influence of the packaging parasitic capacitance on voltage balancing is analyzed; in Section 3, the proposed multi-step package (MSP) concept is presented, where a new package geometry is investigated to reconfigure the packaging parasitic capacitance network. A sensitive analysis is used to estimate the impacts of the delay between gate signals and device parameter mismatch on the proposed MSP. The experimental analyses of the classical planar and MSP are presented in Section 4. In Section 5, a brief thermal management discussion is presented in order to clarify the MSP limitations and indicate the ways to optimize the MSP from a thermal point of view.

\section{Impact of Traditional Planar Packaging Parasitic Capacitances on Voltage Balancing}

To analyze the influence of parasitic capacitances introduced by the classical packaging/layout, a cross-section of a simplified planar package and its main elements are shown in Figure 1, which includes a base-plate, a Direct Bonded Copper (DBC) substrate, and two vertical series-connected SiC-MOSFETs.

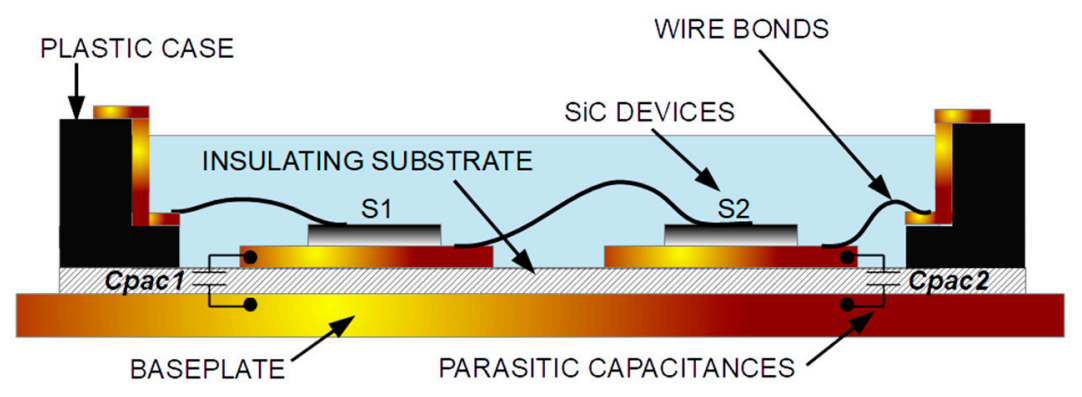

Figure 1. Cross-section of a simplified standard 2D planar package with two dies connected in series [13]. 
In terms of voltage balancing and switching speed performances, the drain-attached copper trace to ground parasitic capacitances $\left(C_{p a c}\right)$ introduced by the packaging is critical. This parasitic capacitance is a key point in the voltage balancing analysis performed in this work. In Figure 1, two series-connected devices are considered in a traditional planar package. Therefore, two parasitic capacitances $\left(C_{p a c 1}\right.$ and $\left.C_{p a c 2}\right)$ are introduced, which represent the modelling of the copper traces attached to the drain in front of the baseplate.

To analyze the influence of the parasitic capacitances $C_{p a c}$ on the dynamic voltage unbalancing and on the switching speed behavior of the switching cell, an electrical scheme of four SiC-MOSFETs connected in series is considered and shown in Figure 2. Where $C_{p a c 1}, C_{p a c 2}, C_{p a c 3}$, and $C_{p a c 4}$ are the drain-to-heatsink parasitic capacitances introduced by the packaging. $C_{\mathrm{DC}+}$ and $\mathrm{C}_{\mathrm{DC}-}$ are the parasitic capacitances from the DC bus to the ground. During the switching events, large current spikes flow from the floating potential nodes to the ground through the heatsink. These currents cause EMI issues, which limit the switching speed of the circuit $[15,16]$. In [17], the use of Y-capacitors $\left(C_{Y}\right)$ is suggested to suppress this EMI. $C_{Y}$ are usually placed between +VDC and GND, and -VDC and GND. It is important to note that, for security reasons, the heatsink is attached to the reference potential of the remote-control circuit (GND), not to -VDC.

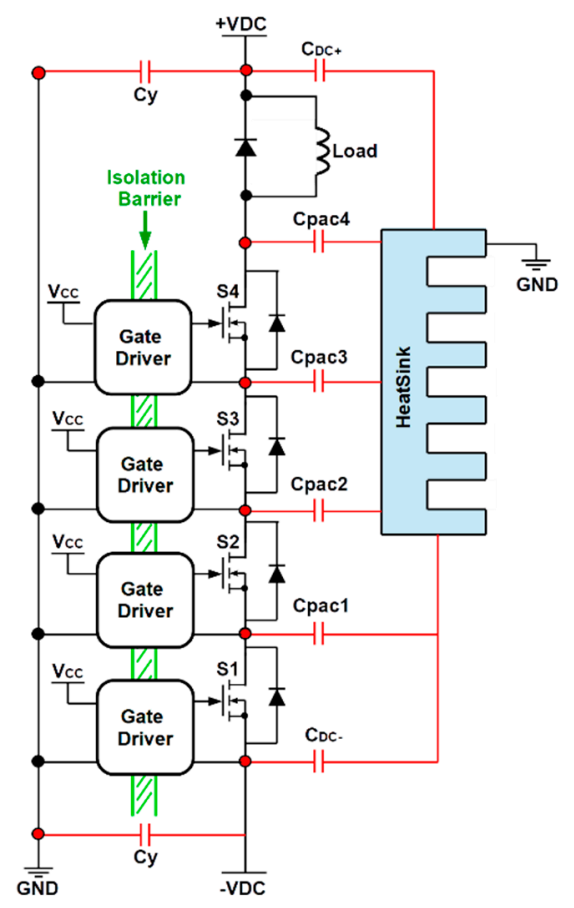

Figure 2. Equivalent electrical scheme of four SiC-MOSFETs connected in series in a 2D planar package.

The capacitors $C_{p a c 1}, C_{p a c 2}, C_{p a c 3}$, and $C_{p a c 4}$ shown in Figure 2 are roughly all the same. However, the $d v / d t$ applied to each of them is different with respect to the position of the device in the stack. Therefore, each parasitic capacitor carries a parasitic current that is getting greater and greater with the device number in the stack (starting from the bottom). The capacitors that generate these currents can be estimated based on the planar capacitance Equation (1).

$$
C_{p a c}=\epsilon \frac{A}{d}
$$

where $\epsilon$ is the absolute permittivity of the isolated substrate, $A$ is the area of the copper trace on which the $\mathrm{SiC}$ device is attached, and $d$ is the distance between the copper plate and the baseplate.

Considering that all SiC-MOSFETs in Figure 2 are identical, and $C_{p a c 1}=C_{p a c 2}=C_{p a c 3}=C_{p a c 4}=C_{p a c}$, Figure 2 can be redrawn as shown in Figure $3 a$, where $C_{d}$ is the intrinsic parasitic capacitance of the 
diode, and $C_{S}$ is the intrinsic equivalent parasitic capacitance of each SiC-MOSFET, which is expressed by Equation (2). In the following analyses, it is supposed that the series-connected SiC-MOSFETs are turning off, and the drain-to-source voltages of the series-connected devices are starting to rise. In other words, the device gate-to-source voltages are under the Miller Plateau region.

$$
C_{S}=C_{g d}+C_{d s}
$$

As shown in Figure 3b, a high-frequency equivalent circuit can be simplified by short-circuiting the DC-bus terminals and CY capacitors. Redrawing Figure 3b, a further simplified high-frequency equivalent scheme can be achieved as shown in Figure $3 c$, where $C_{e q 1}, C_{e q 2}, C_{e q 3}$, and $C_{e q 4}$ are, respectively, the equivalent drain-to-source capacitances of devices S1, S2, S3, and S4, which are expressed by Equations (3)-(7).

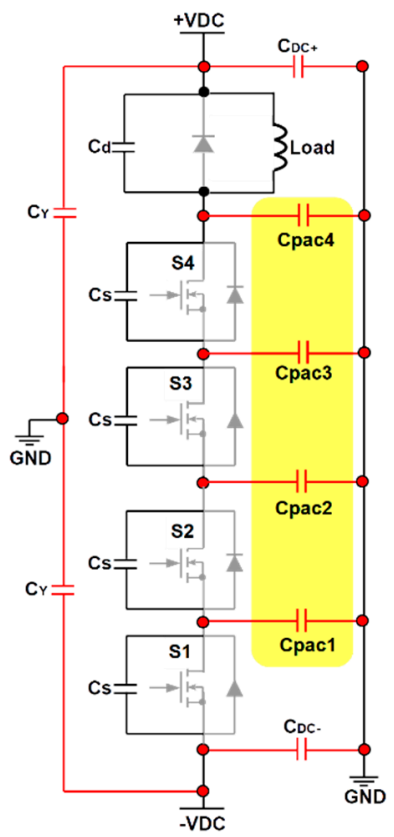

(a)

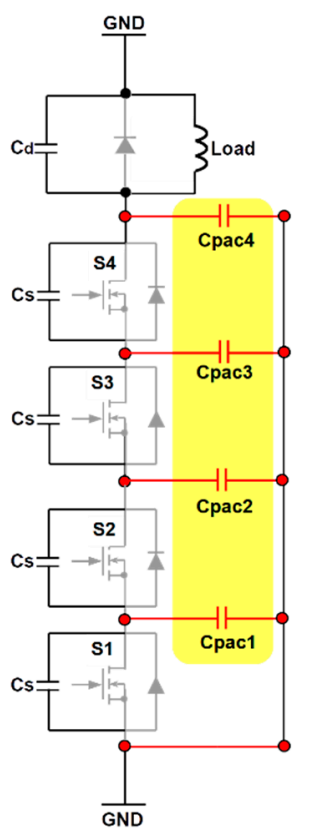

(b)

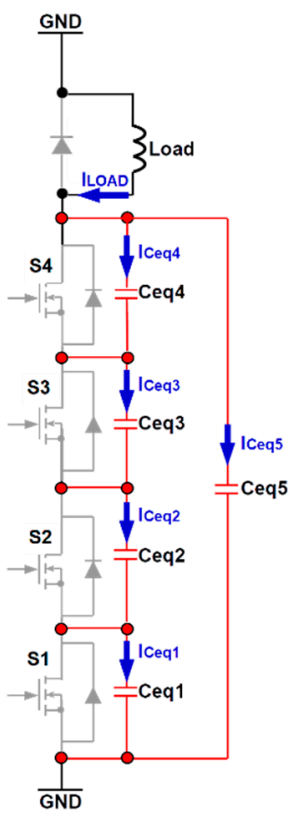

(c)

Figure 3. Equivalent electrical circuits for four series-connected devices (a) and its simplified circuits (b) and (c).

$$
\begin{gathered}
C_{e q 1}=\left(C_{s}+C_{p a c}\right) \frac{C_{s}^{3}+9 C_{s}^{2} C_{p a c}+6 C_{s} C_{p a c}^{2}+C_{p a c}^{3}}{C_{s}^{3}+6 C_{s}^{2} C_{p a c}+5 C_{s} C_{p a c}^{2}+C_{p a c}^{3}} \\
C_{e q 2}=\frac{C_{s}^{3}+9 C_{s}^{2} C_{p a c}+6 C_{s} C_{p a c}^{2}+C_{p a c}^{3}}{C_{s}^{2}+6 C_{s} C_{p a c}+2 C_{p a c}^{2}} \\
C_{e q 3}=\left(C_{s}+C_{p a c}\right) \frac{C_{s}^{3}+9 C_{s}^{2} C_{p a c}+6 C_{s} C_{p a c}^{2}+C_{p a c}^{3}}{C_{s}^{3}+8 C_{s}^{2} C_{p a c}+8 C_{s} C_{p a c}^{2}+2 C_{p a c}^{3}} \\
C_{e q 4}=\left(C_{s}+C_{p a c}\right) \frac{C_{s}^{3}+9 C_{s}^{2} C_{p a c}+6 C_{s} C_{p a c}^{2}+C_{p a c}^{3}}{C_{s}^{3}+9 C_{p a c}+9 C_{s} C_{p a c}^{2}+2 C_{p a c}^{3}} \\
C_{e q 5}=C_{d}
\end{gathered}
$$

In Figure $4 \mathrm{a}$, the behavior of each equivalent parasitic capacitance as a function of $C_{p a c}$ for $C_{s}=$ $100 \mathrm{pF}$ is shown. This value is based on the datasheet of the device used in this work (C2M0160120 
$(1200 \mathrm{~V}, 19 \mathrm{~A})$. As can be seen, the device at the top of the stack (S4) has the smallest equivalent capacitance $\left(C_{e q 4}\right)$, whatever the $C_{p a c}$ value is. On the other hand, the first device in the stack (S1) has the greatest equivalent capacitance $\left(C_{e q 1}\right)$. Note that, the higher the device is positioned on the stack, the lower its drain-to-source equivalent capacitance is. The switching speed behavior of each device is also a function of its position in the stack as shown in Figure $4 \mathrm{~b}$. In other words, the device at the top of the stack (S4) has the fastest switching speed, while S1 (the first one in the stack) has the slowest $d v / d t$. This phenomenon has been observed in experimental results presented in the literature $[3,7,9,11]$.

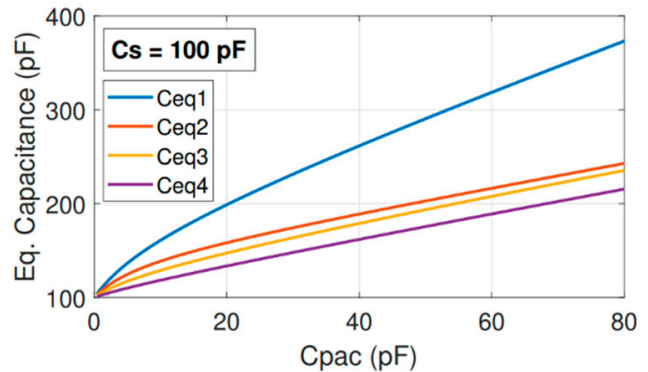

(a)

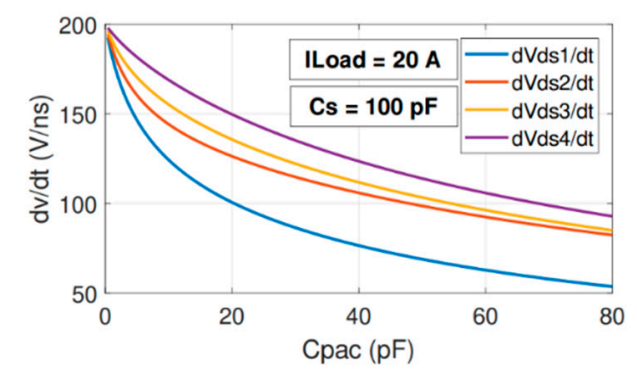

(b)

Figure 4. Equivalent parasitic capacitances (a) and switching speed behavior (b) as a function of $C_{p a c}$.

As can be seen in Figure $4 \mathrm{~b}$, the devices have different switching speeds $(d v / d t)$ and, therefore, their voltages are dynamically unbalanced.

\section{Electrical Transient Simulations: Traditional Planar Packaging}

To validate the theoretical analyses done in the previous section, electrical simulations are made in LTSpice $^{\mathrm{TM}}$ software with four Cree ${ }^{\mathrm{TM}}$ SiC-MOSFET Spice models C2M0160120 (1200V 19 A), which are switched under a total blocking voltage of $1 \mathrm{kV}$ and a load current of $20 \mathrm{~A}$. The simulations are done in the hypothetical case where the gate drivers are perfect, there is no time delay between the gate signals, and the power devices are identical. In other words, only the packaging/layout (capacitive elements) is taken into account. In Figure 5, the simulation results for the traditional packaging/layout are shown.
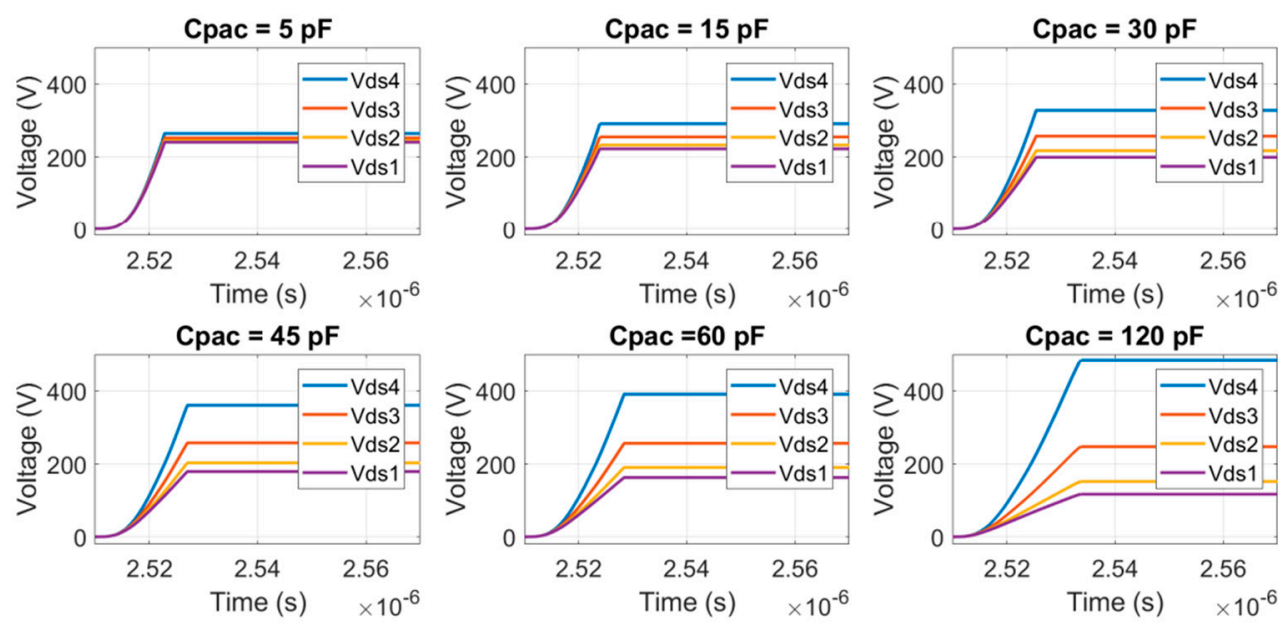

Figure 5. Simulation results of voltage-sharing performance between four series-connected $\mathrm{SiC}-\mathrm{MOSFETs}$ in classical packaging/layout.

As expected, the voltage sharing in traditional packaging/layouts is drastically sensitive to the parasitic capacitances $C_{p a c}$. In Figure 5 for $C_{p a c}=5 \mathrm{pF}$, an acceptable voltage unbalancing is presented. However, $C_{p a c}=5 \mathrm{pF}$ is not a practical value; in traditional PCBs, $C_{p a c}$ can reaches a few dozen $\mathrm{pF}$, 
while in power modules, $C_{p a c}$ can reach a few hundred $\mathrm{pF}$ [18]. In this case, as shown in Figure 5, from $C_{p a c}=30 \mathrm{pF}$ to $120 \mathrm{pF}$, traditional packaging/layout exacerbates voltage balancing problems.

Another characteristic of classical package/layout is its impact on the switching speed of the devices. In Figure 6, the simulation results of the $d v / d t$ of the switching cell as a function of the parasitic capacitance $C_{p a c}$ are shown. A $d v / d t$ reference, which represents the $d v / d t$ for $C_{p a c}=5 \mathrm{pF}$, is placed in Figure 6 to analyze the influence of $C_{p a c}$. As can be seen, the $d v / d t$ on the middle point is drastically reduced when $C_{p a c}$ increases from $5 \mathrm{pF}$ to $120 \mathrm{pF}$. As will be explained in the next section, modifying the parasitic capacitance configuration of the package/layout not only reduces the voltage unbalancing, but also can improve the switching speed of the devices.
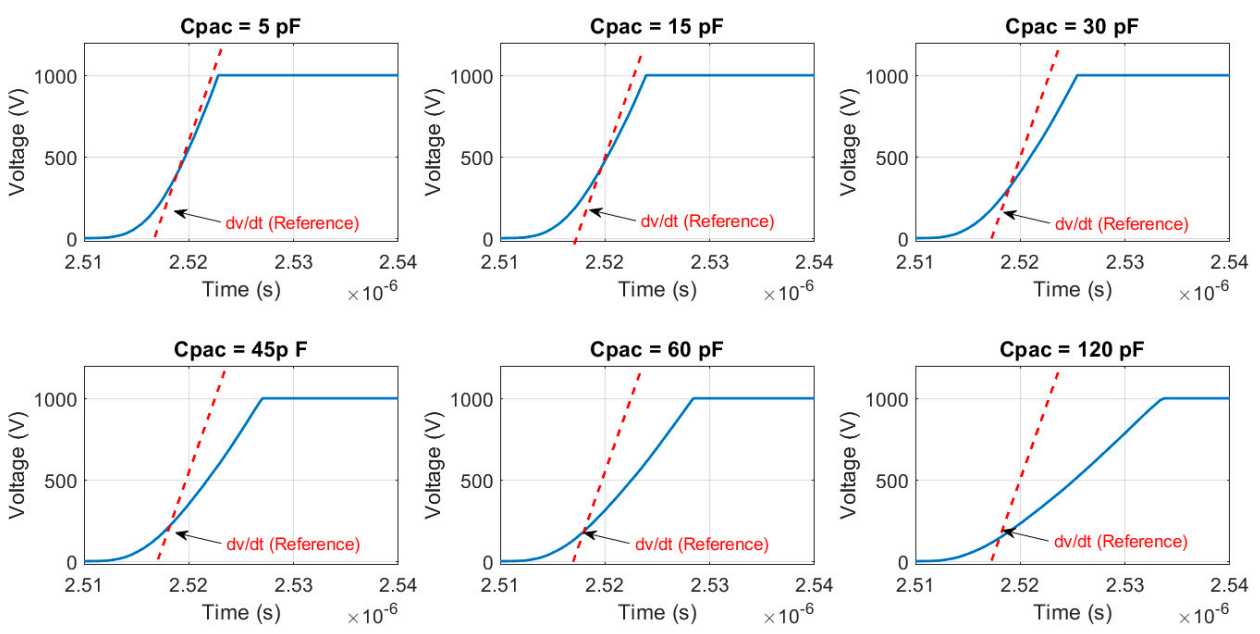

Figure 6. Simulation results of the middle point switching speed as a function of $C_{\text {pac }}$ for the classical packaging/layout.

\section{Impact of Multi-Step Packaging Parasitic Capacitances on Voltage Balancing}

As explained, the classical packaging/layout increases voltage balancing problems, since it generates unequal drain-to-source equivalent parasitic capacitances among the series-connected devices, which carry parasitic currents that get greater and greater with the device number in the stack (starting from the bottom). Therefore, to improve voltage balancing, the equivalent parasitic capacitances shown in Figure $3 \mathrm{c}$ have to be identical, allowing the series-connected devices to have the same dynamic switching behaviors (dv/dt).

To ensure equal drain-to-source equivalent capacitance distribution among the series-connected devices, a multi-step packaging (MSP) concept, shown in Figure 7, is analyzed in this paper. The front and backside die-attachments are implemented in a similar way that is done in the traditional $2 \mathrm{D}$ planar package. As can be seen, in the MSP concept, the parasitic capacitances $C_{\text {pac }}$ are generated by the copper traces (connected to the drain contacts) of the series-connected devices.

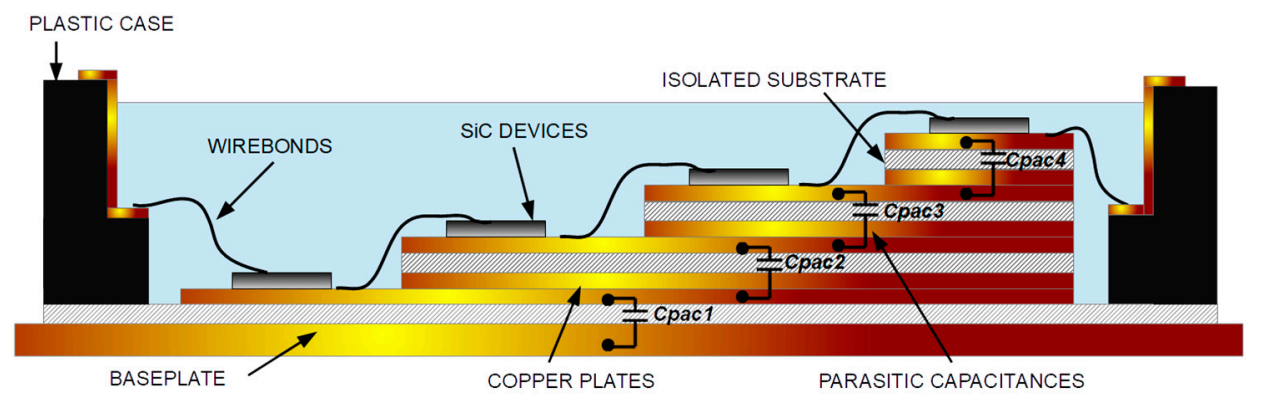

Figure 7. A new multi-step package concept [13]. 
The electrical scheme of the MSP is shown in Figure 8a, where it is supposed that all SiC-MOSFETs are identical, and they are turning off. Note that, in the MSP configuration, the parasitic capacitances $C_{p a c}$ are formed by two subsequent drain-attached copper tracers, i.e., $C_{\text {paci }}$ is the capacitance connected with drain-source terminals of the device $S_{\mathrm{i}}$ (for $\left.i=2,3,4\right)$. As shown in Figure $8 \mathrm{~b}$, the high-frequency equivalent circuit can be simplified by short-circuiting the DC-bus terminals and $C_{Y}$ capacitors. Redrawing Figure 8b, a further simplified high-frequency equivalent scheme can be achieved, as shown in Figure 8c. The equivalent drain-to-source parasitic capacitances of each device are expressed by the Equations (8) and (9).

$$
\begin{gathered}
C_{e q i}=C_{s}+C_{p a c i}, \quad i=1,2,3,4 . \\
C_{e q 5}=C_{d}
\end{gathered}
$$

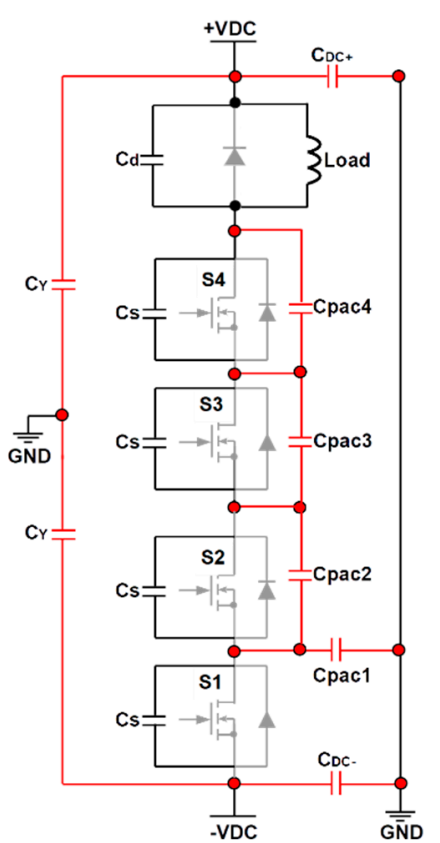

(a)

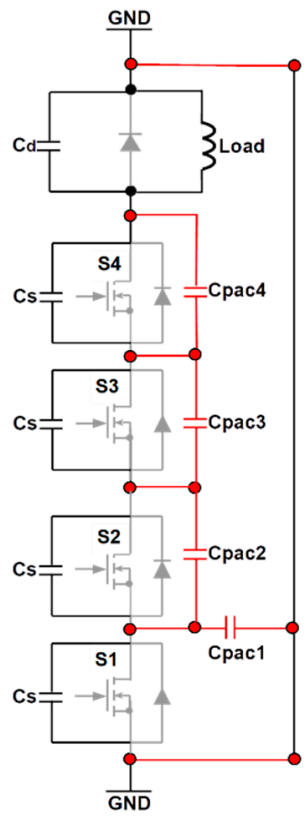

(b)

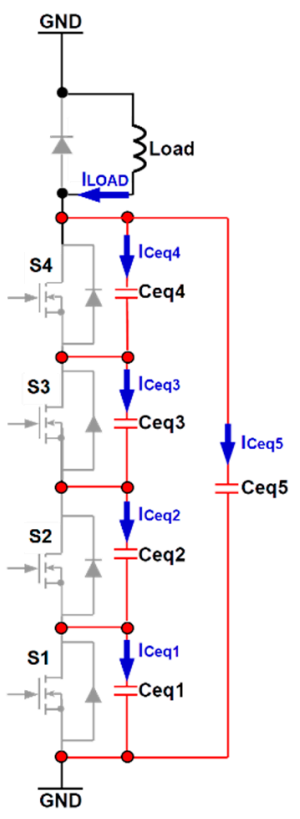

(c)

Figure 8. Electrical scheme of four SiC-MOSFETs connected in series in the MSP (a), high-frequency circuit (b), and simplified electrical scheme (c).

Analyzing Figure $8 \mathrm{c}$, the currents that circulate through the equivalent parasitic capacitances $C_{\text {eqi }}$, can be expressed by the Equations (10) and (11).

$$
\begin{aligned}
I_{C e q i} & =C_{e q i} \frac{d V_{d s i}}{d t} \\
I_{C e q 5} & =C_{e q 5} \frac{d V_{d s 5}}{d t}
\end{aligned}
$$

where $V_{d s i}$ is the drain-to-source voltage across the device $S i$, and $V_{d s 5}$ is the middle point voltage.

To prove that the MSP can balance the voltages, it can be supposed that the voltages across the series-connected devices are perfectly balanced and find the $C_{\text {paci }}$ values that ensure this supposition. Based on this assumption, it can be considered that the channel currents of series-connected devices are identical. Therefore, according to the mentioned considerations and the current distribution shown in Figure $8 \mathrm{c}$, the following equations can be written:

$$
C_{e q 1} \frac{d V_{d s 1}}{d t}=C_{e q 2} \frac{d V_{d s 2}}{d t}=C_{e q 3} \frac{d V_{d s 3}}{d t}=C_{e q 4} \frac{d V_{d s 4}}{d t}
$$




$$
\left(C_{s}+C_{p a c 1}\right) \frac{d V_{d s 1}}{d t}=\left(C_{s}+C_{p a c 2}\right) \frac{d V_{d s 2}}{d t}=\left(C_{s}+C_{p a c 3}\right) \frac{d V_{d s 3}}{d t}=\left(C_{s}+C_{p a c 4}\right) \frac{d V_{d s 4}}{d t}
$$

According to Equation (13), the series-connected SiC-MOSFETs can have the same switching speed behavior if the parasitic capacitances $C_{\text {paci }}$ are identical. Therefore, to ensure an equal equivalent capacitance (drain-to-source) distribution among the series-connected devices, it is important to ensure that the Equation (14) is satisfied, i.e., once the isolated substrates are made of the same material, the ratio $A / d$ has to be the same for all capacitances, where $A$ is the area of the copper trace where the $\mathrm{SiC}$ device is attached, and $\boldsymbol{d}$ is the distance between two subsequent copper plates.

$$
C_{p a c}=\epsilon \frac{A}{d}=C_{p a c 1}=\epsilon \frac{A_{1}}{d_{1}}=C_{p a c 2}=\epsilon \frac{A_{2}}{d_{2}}=C_{p a c 3}=\epsilon \frac{A_{3}}{d_{3}}=C_{p a c 4}=\epsilon \frac{A_{4}}{d_{4}}
$$

Figure 9 shows two 3D representations of the MSP that satisfy Equation (14). Figure 9a shows a simple MSP/layout where the copper area $(A)$ of each floating potential is different from the others, assuming that the dielectric material thickness $(d)$ between them are the same. This simple solution induces different parasitic capacitances, since they have different ratios $(A / d)$. Therefore, according to Equations (13) and (14), the voltage balancing cannot be ensured. In the second MSP geometry shown in Figure $9 b$, the thicknesses of the dielectric material layer are adapted to keep the ratio $A / d$ the same for all drain-to-source parasitic capacitances $C_{p a c}$, respecting the Equations (13) and (14). Another solution is to keep the same distance $d$ between all overlapping copper plates and the same area $A$ to ensure the same ratio $A / d$ for all drain-to-source parasitic capacitances.

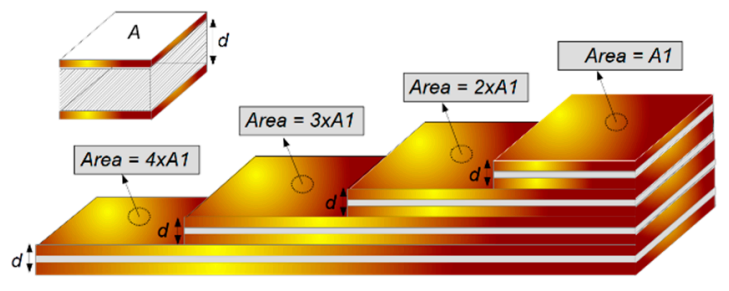

(a)

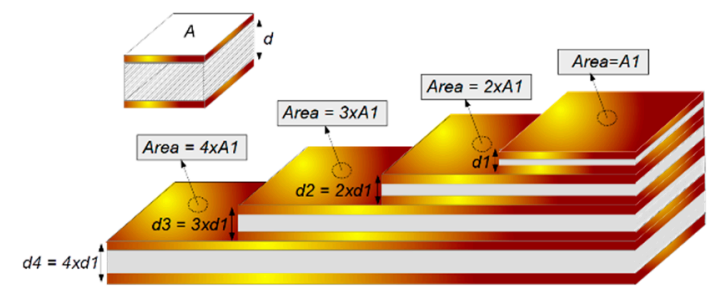

(b)

Figure 9. 3D view of the proposed package concept with the same distance $\boldsymbol{d}(\mathbf{a})$ and different distances $d(\mathbf{b})[13]$.

Therefore, considering that the parasitic capacitances $C_{p a c}$ have the same value for all the series-connected devices, the Equation (13) becomes:

$$
\left(C_{s}+C_{p a c}\right) \frac{d V_{d s 1}}{d t}=\left(C_{s}+C_{p a c}\right) \frac{d V_{d s 2}}{d t}=\left(C_{s}+C_{p a c}\right) \frac{d V_{d s 3}}{d t}=\left(C_{s}+C_{p a c}\right) \frac{d V_{d s 4}}{d t}
$$

In this case, the negative impacts of the packaging/layout on voltage balancing are nullified, and the stacked devices can have the same switching speed behavior.

\subsection{Electrical Transient Simulations of the Multi-Step Packaging}

To validate the theoretical multi-step approach, electrical simulations are made in LTSpice ${ }^{\mathrm{TM}}$ software with four Cree ${ }^{\mathrm{TM}}$ SiC-MOSFET Spice models C2M0160120 (1200 V 19 A), which are switched under a total blocking voltage of $1 \mathrm{kV}$ and a load current of $20 \mathrm{~A}$. The simulations are done in the hypothetical case where the gate drivers are perfect, no time delay between the gate signals is presented, and the power devices are identical. In other words, only the packaging/layout (capacitive elements) is taken into account. The simulation results are shown in Figure 10.

As can be seen, the MSP is not sensitive to $C_{p a c}$ in terms of voltage sharing among the series-connected devices, as shown in Figure 10. Even for exacerbated values of $C_{\text {pac }}$, the bus voltage is perfectly shared between the devices. The switching speed of the switching cell is also 
improved in the proposed MSP concept when compared to the traditional one. Figure 11 shows the $d v / d t$ as a function of $C_{p a c}$ for the traditional (TRP) and MSPs/layouts. In the TRP, the parasitic capacitances $C_{\text {pac }}$ drastically impact the $d v / d t$ of the switching cell. On the other hand, the MSP concept is less sensitive to $C_{p a c}$. This is due the fact that in the TRP, the currents that circulate through the parasitic capacitances $C_{p a c}$ are deflected from the switching cell to the ground or heatsink. In other words, a part of the currents that would be used to charge/discharge the device capacitances is deflected to the ground, slowing down the device switching speeds. On the other hand, in the MSP geometry, the currents that circulate through the parasitic capacitances $C_{p a c}$ are returned locally to the switching cell.
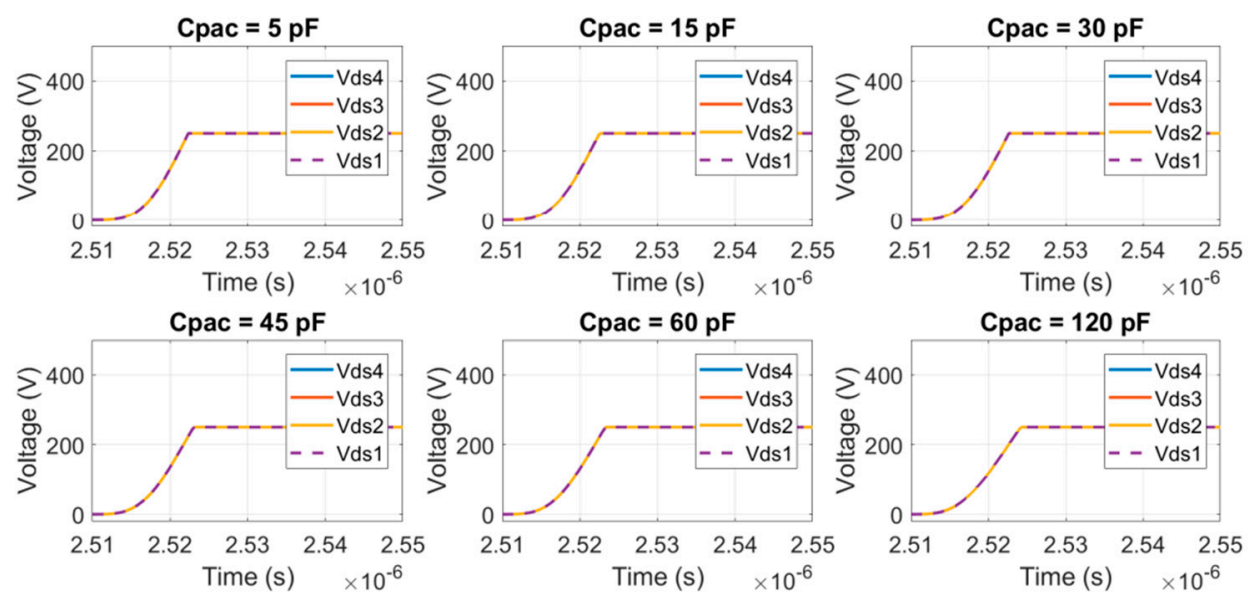

Figure 10. Simulation results of voltage-sharing performance between four series-connected SiC-MOSFETs in MSP.
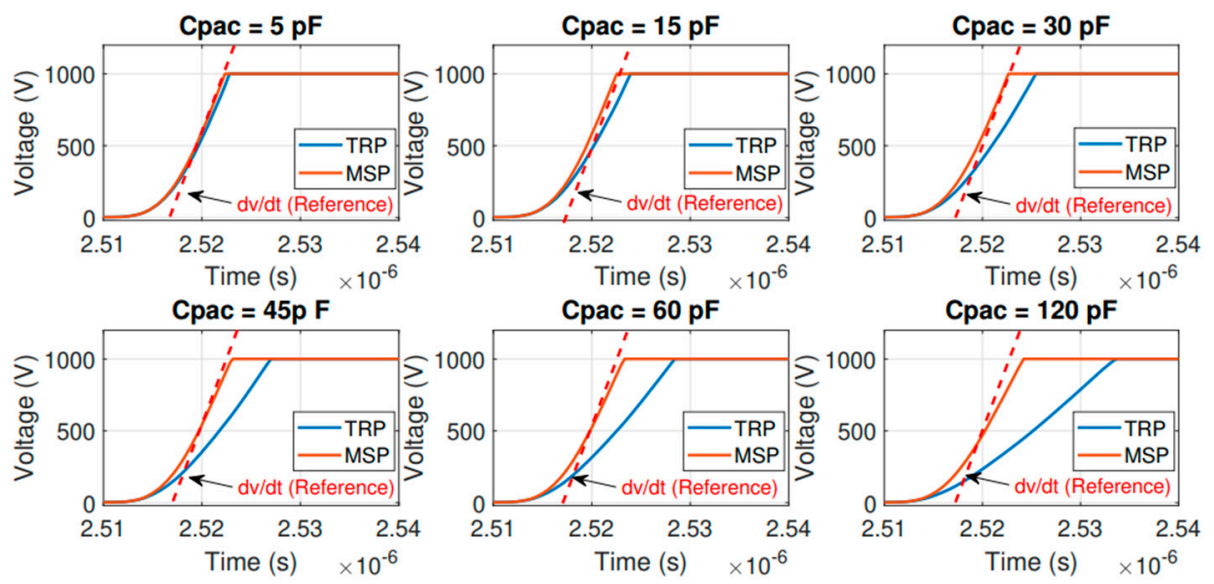

Figure 11. $d v / d t$ as a function of Cpac for TRP and MSPs/layouts.

\subsection{Delay Time and Device Parameter Tolerance Sensitive Analysis}

Up to now, it has been considered that there is no delay between the gate signals and no device parameter mismatch between the series-connected devices. Characterization and careful selections of SiC-MOSFETs can reduced the mismatch between SiC-MOSFET intrinsic capacitances. Optimized gate driver circuitry can mitigate the delay between gate signals. However, if these optimizations are not taken into account, it can drastically impact the MSP performance on voltage balancing. Therefore, a sensitive analysis is done in this section to estimate the impacts of the delay between gate signals and device parameter mismatch on the proposed MSP. Only two series-connected SiC-MOSFETs are analyzed so as to simplify the preliminary analysis. 
To analyze the robustness of the MSP in terms of voltage balancing, the following parameters are used to perform the sensitive analysis:

- $\Delta \mathrm{Cgs}, \Delta \mathrm{Cgd}$, and $\Delta \mathrm{Cds}$, which represent the differences between the intrinsic capacitances of the series-connected devices. The values used in the analysis are based on a study performed in $[17,19]$.

- $\Delta \mathrm{Rg}$, which represents the difference between the internal gate resistances of the devices. The values used in the analysis are based on a study performed in [19].

- Delay, which represents the delay between the gate signals.

- $\Delta \mathrm{T} j$, which represents the junction temperature difference between the devices. As will be explained in this paper, in the MSP, each device has a different thermal resistance. Therefore, it can also impact the voltage balancing across the devices.

Two C2M ${ }^{\mathrm{TM}}$ SiC-MOSFETs C2M0160120 (1200 V 19 A) are used in the analysis, where the top device parameters are fixed, and the parameter variations are imposed to the bottom device. The gate resistances are initially set to $10 \Omega$. The MSP parasitic capacitances are set to $30 \mathrm{pF}$. The series-connected devices are switched under a total blocking voltage of $1 \mathrm{kV}$ and a load current of $20 \mathrm{~A}$. The analysis is done in relation to the voltage across the top device, i.e., how much the top device voltage increases from the ideal voltage (half the bus voltage) to the final value caused by the parameter variation. The results, expressed in percentage (\%), are shown in Figure 12. As can be seen, the mismatch between the intrinsic capacitances $C_{g s}$ slightly impacts the voltage balancing. Every $20 \mathrm{pF}$ of difference, the top device voltage increases only by $2 \%$. The mismatch between the intrinsic capacitances $C_{d s}$ has a similar impact on voltage balancing. On the other hand, the mismatch between the intrinsic capacitances $C_{g d}$ drastically increases the voltage unbalancing. For $\Delta \mathrm{C}_{\mathrm{gd}}=20 \mathrm{pF}$ the top device voltage increases by $40 \%$. In other words, if the bus voltage is equal to $1 \mathrm{kV}$, the top devices experience a drain-to-source voltage of $700 \mathrm{~V}$. This is understandable, since during the switching transition (Miller plateau, $v_{d s}$ rising/falling), the switching speed behavior is very dependent of $C_{g d}$, i.e., the switching speed represents the necessary time to charge/discharge $C_{g d}$.
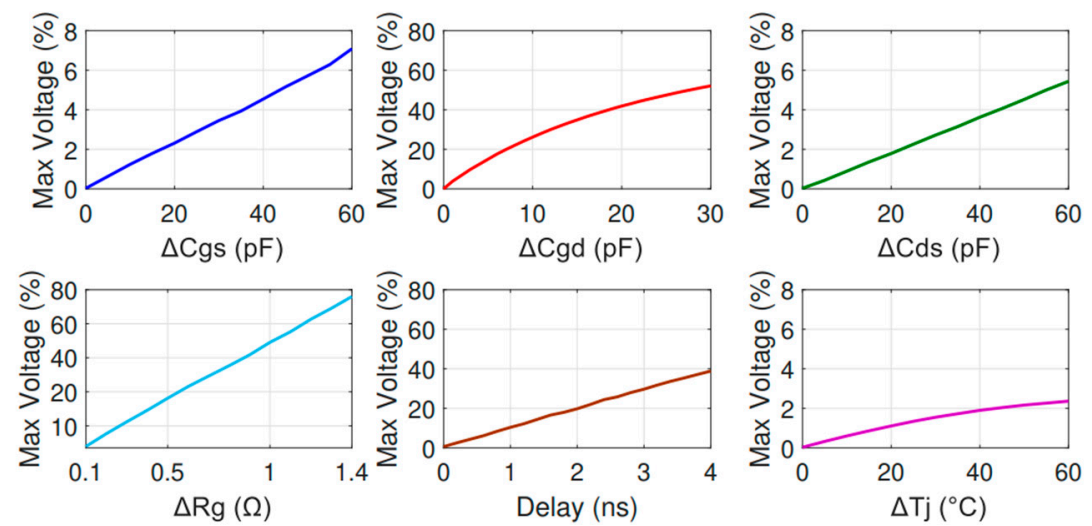

Figure 12. Sensitive analysis results.

The mismatch between internal gate resistances also drastically impacts voltage unbalancing. A $\Delta \mathrm{R}_{\mathrm{g}}=0.5 \Omega$ is enough to increase the top voltage device by $20 \%$. Unlike the device-intrinsic capacitances, the device's internal gate resistance is constant and does not dependent on $V_{d s}$ voltage. After a careful device characterization, the mismatch between internal gate resistances can be compensated by external ones.

The delays between gate signals have also an important influence on the voltage balancing. As can be seen in Figure 12, four nanoseconds are enough to increase the top device voltage unbalance of $40 \%$. Therefore, optimized gate signal circuitry is required to improve the voltage balancing across the series-connected SiC-MOSFETs. 
The junction temperature difference among the devices is another important parameter for the MSP, since each device in the stack has a different thermal resistance. The main device parameters that are influenced by the junction temperature $T_{j}$ are the drain-to-source current $I_{D S}$, the drain-to-source on-state resistance $R_{D S o n}$, and the threshold voltage $V_{T H}$. However, according to the SiC-MOSFET C2M0160120 datasheet, a large variation on the junction temperature to generate proportional variations on the device parameters is necessary. For example, according to C2M0160120 datasheet, the $V_{T H}$ variation as a function of $T_{j}$ is only $0.005 \mathrm{~V} /{ }^{\circ} \mathrm{C}$. This robust stability is validated by simulation results, as can be seen in Figure 12, where even for exacerbated values of $\Delta \mathrm{T}_{\mathrm{j}}$ the top device voltage does not increase considerably.

Based on the sensitive analysis shown in Figure $12, \Delta C_{g d}, \Delta R_{g}$, and $\Delta$ delay are the three most important parameters that can considerably increase voltage balancing problems. In order to analyze the impact of $C_{g d}, \Delta R_{g}$, and $\Delta$ delay on voltage balancing, Figure 13 shows the sensitive analysis of these three parameters, where their variations are analyzed together. The main idea is to vary, at the same time, $\Delta \mathrm{C}_{\mathrm{gd}}, \Delta \mathrm{R}_{\mathrm{g}}$, and $\Delta$ delay in order to reach the worst case and then to know the acceptable device mismatch limits. The analysis is done for four values of $\Delta R_{g}: 0.2,0.3,0.4$, and $0.5 \Omega$. The $\Delta C_{g d}$ is changed from 0 to $4 \mathrm{pF}$, and $\Delta$ delay from 0 to $1 \mathrm{~ns}$. The analysis is done in the same manner presented in Figure 12, i.e., it is investigated how much the top device voltage increases from the ideal voltage (half the bus voltage) to the final value caused by the parameter variation.
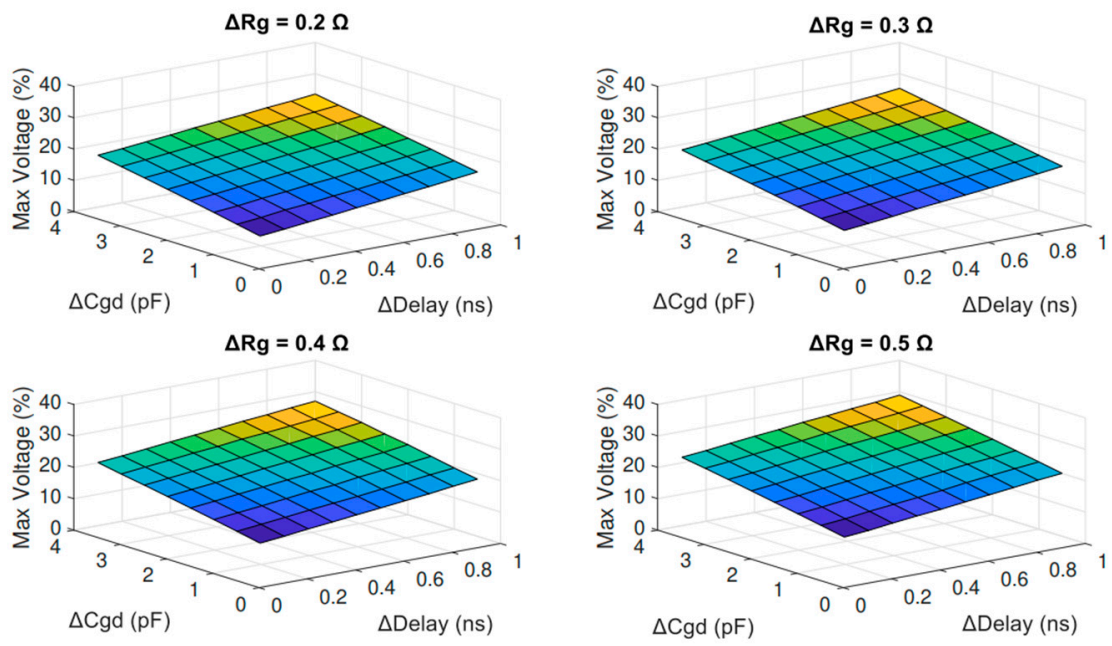

Figure 13. Sensitive analysis results as a function of $\Delta R_{g}, \Delta C_{g d}$, and $\Delta$ Delay.

As can be seen in Figure 13, the MSP can provide good voltage balancing if these parameters are limited according to acceptable levels of voltage unbalancing. For example, supposing that it is acceptable that the top device in the stack takes $20 \%$ more than the ideal voltage (half the bus voltage), and $\Delta \mathrm{R}_{\mathrm{g}}$ is limited to $0.2 \Omega$. For $\Delta \mathrm{C}_{\mathrm{gd}}$ values $\leq 4 \mathrm{pF}$ and $\Delta$ delay values $\leq 0.4 \mathrm{~ns}$, the top device voltage will not increase more than $20 \%$, ensuring a good and acceptable voltage balancing across the series-connected SiC-MOSFETs.

It is important to note that the faster the SiC-MOSFETs switch, the more the parameters impact the voltage balancing. The sensitive analysis presented here is done under a hard switching operation, where discrete device models (C2M0160120) are used. For power devices that switch more slowly, such as some $\mathrm{SiC} / \mathrm{Si}$ power modules or IGBTs, these parameters have less influence, and the MSP is less sensitive to the parameter mismatches. On the other hand, for devices that switch very quickly, such as GaN transistors, the analyzed parameters have more influence, and the MSP is more sensitive to the parameter mismatches. 


\section{Experimental Results}

To investigate the theoretical approach proposed in this paper, two prototypes have been developed. These prototypes, i.e., the MPS package and planar one, are built thanks to stacked FR4 layers so as to verify the electrical behaviors without thermal considerations. Therefore, these prototypes are used in a pulsed mode to avoid a significant temperature increase in the SiC-MOSFETs. The developed prototypes meet the following requirements:

- $\quad$ Each copper plate where each $\mathrm{SiC}$ device is attached has the same area-A $=10 \mathrm{~cm}^{2}$.

- The FR4 dielectric thicknesses between two copper plates, which generate each Cpac, are all the same- $\mathrm{d}=1.5 \mathrm{~mm}$.

- The isolated substrates are made of the same FR4 material, and they have the same absolute permittivity- $\epsilon=45 \mathrm{pF} / \mathrm{m}$.

- The measured parasitic capacitances between two copper plates are almost the same for the MSP prototype-Cpac $=30 \mathrm{pF}$ (discrepancy $<5 \%$ between these capacitances).

- The traditional packaging also introduces a parasitic capacitance $\mathrm{Cpac}$ of $30 \mathrm{pF}$.

As shown in Figure 14, a switching cell with four series-connected SiC-MOSFETs C2M0160120 $(1200 \mathrm{~V}, 19 \mathrm{~A})$ and one diode STPSC40H12CWL $(1200 \mathrm{~V}, 20 \mathrm{~A})$ has been used to investigate the influence of the traditional packaging and the proposed package concept on the voltage balancing and on $d v / d t$. A bus voltage of $1 \mathrm{kV}$ and a load current of $20 \mathrm{~A}$ have been used in the experiments. No external drain-to-source resistor are added to provide static voltage balancing. In order to mitigate the impact of the gate driver to ground parasitic capacitances in the set-up experiments [3], the gate drivers shown in Figure 14 are powered by batteries.

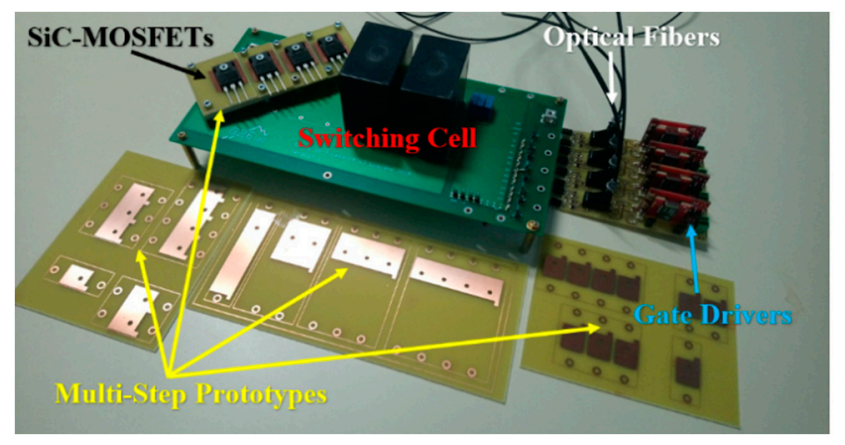

Figure 14. Switching cell and MSP prototypes.

The delay time and the effects of voltage probes are compensated by a specific calibration process, where the power devices are left with no connection to the FR4 package. In this situation, it is supposed that the parasitic capacitance $C_{p a c}$ has an ultra-low value, although it is probably still different to zero. Adaptative open-loop external delay and gate resistance circuits are implemented to achieve a perfect voltage sharing between the devices. In this case (CASE 1), all effects generated by the gate drivers, voltage probes, the different characteristics between the devices, etc., are compensated. The switching speed calibration result is illustrated in Figure 15. As can be seen in Figure 15a, balanced voltages of around $250 \mathrm{~V}$ are achieved with a very small discrepancy $(<15 \mathrm{~V})$ between them. In Figure $15 \mathrm{~b}$, the zoomed dynamic phase is shown. These waveforms are the reference point to analyze the classical planar package and the MSP one, since these results are achieved without any FR4 package. The results shown in Figure 15 are in accordance with the theoretical analysis presented in Section 2. It can be verified making $C_{\text {pac }}$ tend to zero in Equations (3)-(6). In this case, the series-connected SiC-MOSFETs have the same drain-source equivalent parasitic capacitance $\left(C_{S}\right)$ and, therefore, the same switching speed behavior, leading to balanced voltages across the devices. 
According to the theoretical analyses presented in this paper, the parasitic capacitances introduced by the classical planar packaging can unbalance the voltages across the series-connected SiC-MOSFETs, even if there are no delays between gate signals and no mismatch between the characteristics of the series-connected devices. This theoretical analysis is experimentally validated, as shown in Figure 16. According to the Equations (3)-(6) and Figure 4, when the classical planar packaging is implemented for the device's assembly and interconnects (CASE 2), unequal $d v / d t$ that are a function of the position of devices in the stack, are applied to the parasitic capacitances introduced among the series-connected SiC-MOSFETs. It produces parasitic currents that are also a function of the position of devices in the stack. As expressed in the theoretical analysis, the experiments validate that behavioral representation leads to voltage balancing problems, as shown in Figure 16. As can be seen in Figure 16a, the parasitic capacitances introduced by the traditional planar package produce an important voltage unbalancing. A considerable voltage difference of around $110 \mathrm{~V}$ is observed between the drain-to-source voltages $\left(V_{d s 4}-V_{d s 1}\right)$ across the series-connected devices. Note that, the parasitic capacitance $C_{p a c}$ in the traditional package prototype is only $30 \mathrm{pF}$. Classical power modules can introduce a few hundred $\mathrm{pF}$, which will exacerbate voltage balancing problems. Figure $16 \mathrm{~b}$ shows the zoomed view at turn-off. As mentioned in this paper, and according to the Equations (3)-(6) and Figure 4, the highest device on the stack takes the largest portion of the bus voltage. This phenomenon repeats itself in the present experiments where $V_{d s}$ is approximately equal to $360 \mathrm{~V}$, which represents approximately $44 \%$ more than the ideal voltage $(250 \mathrm{~V})$.

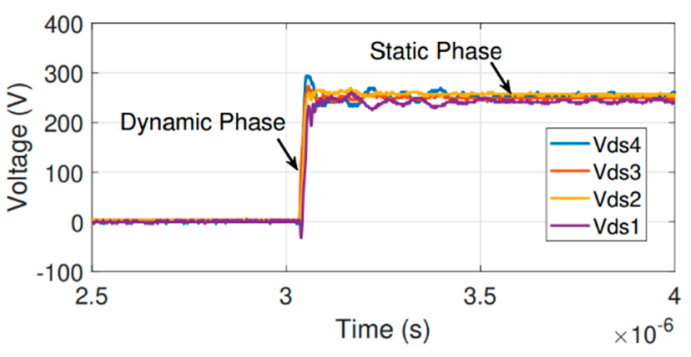

(a)

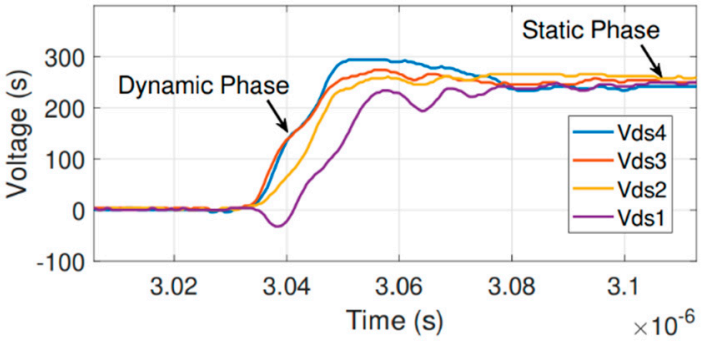

(b)

Figure 15. Voltage balancing achieved by the calibration process without FR4 package (a) and its zoomed view (b); CASE 1.

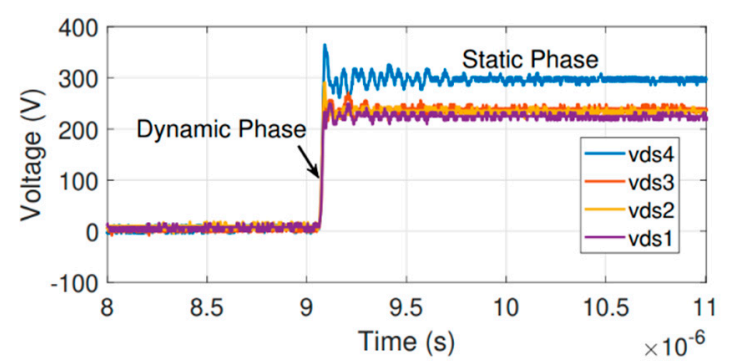

(a)

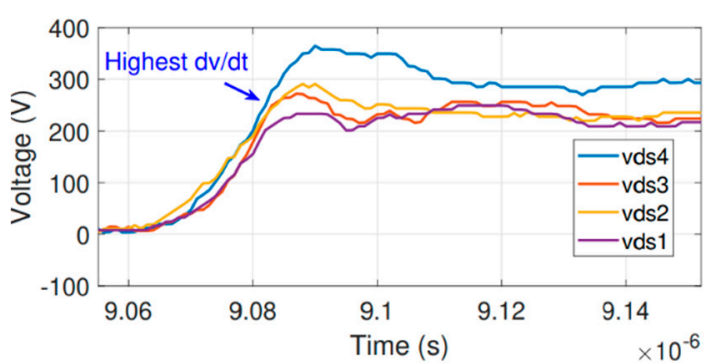

(b)

Figure 16. Voltage balancing after adding the traditional planar package (a) and its zoomed view (b); CASE 2.

Figure 17 shows the experimental results when the MSP is attached to the switching cell (CASE 3). As expected, the voltage unbalancing has been drastically reduced. A small voltage difference of around $31 \mathrm{~V}$ is observed between the drain-to-source voltages $\left(V_{d s 4}-V_{d s 1}\right)$ across the devices. As well as in CASE 2, the highest device on the stack (S4) still takes the largest portion of the DC bus voltage. However, in CASE 3, the $\mathrm{V}_{\mathrm{ds} 4}$ is approximately $265 \mathrm{~V}$. It represents no more than $6 \%$ in relation to the ideal voltage $(250 \mathrm{~V})$. These results are in accordance with the theoretical analysis presented in Section 3, i.e., the MSP introduces equal drain-source equivalent parasitic capacitances across the 
series-connected SiC-MOSFETs. In addition, $d v / d t$ are not anymore dependent of the device number in the stack, which implies the same switching speed behavior among them as described by Equation (15). Therefore, the voltage balancing problems introduced by the package capacitances are drastically reduced, as shown in Figure 17.

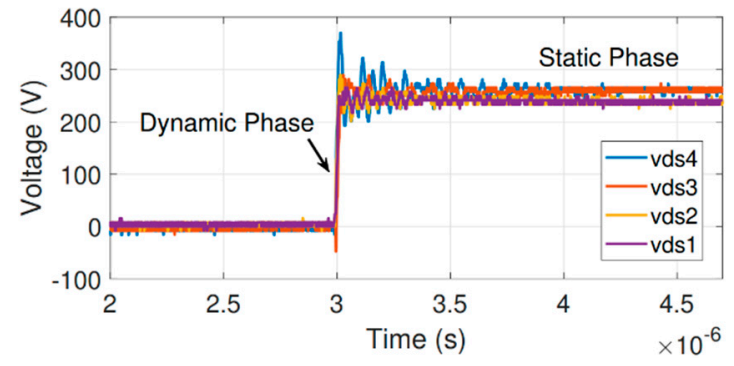

(a)

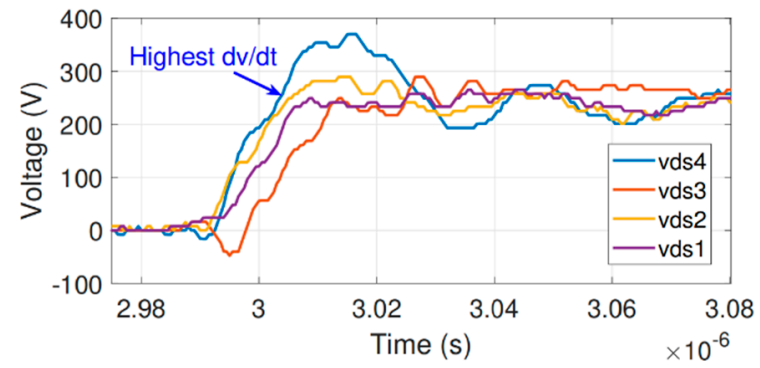

(b)

Figure 17. Voltage balancing after adding the proposed MSP (a) and its zoomed view (b); CASE 3.

Note that, in the three cases, the peak voltage during the turn-off switching is caused by the stray inductance of the switching cell. In this case, as no static resistors are used in the experiments, the discrepancy between the $V_{d s}$ voltages is measured after the ringing voltage.

In Section 3, the simulation results depicted in Figure 11 show that the MSP can increase the middle point switching speed when compared to the TRP one. These results are also experimentally validated. In Figure 18, the experimental results for both packages in terms of $d v / d t$ are shown. As can be seen, the switching speed on the middle point of the switching cell has been boosted from $50.0 \mathrm{~V} / \mathrm{ns}$ to $69 \mathrm{~V} / \mathrm{ns}$. It represents a gain of $38 \%$ on the $d v / d t$ of the switching cell, which may produce a significant gain in terms of switching losses. These results can be explained by the theoretical analyses represented by Figures $3 b$ and $8 b$. In the TRP represented by Figure $3 b$, the currents that circulate through the parasitic capacitances $C_{p a c}$ are deflected from the switching cell to the ground or heatsink. Therefore, a part of the currents that would be used to charge/discharge the device capacitances is deflected to the ground, slowing down the device switching speeds. On the other hand, in the MSP geometry represented by Figure $8 \mathrm{~b}$, the currents that circulate through the parasitic capacitances $C_{\text {pac }}$ are all equal and they return locally to the switching cell, which maintains the switching speed of all the devices in the stack when compared to the classical planar package.

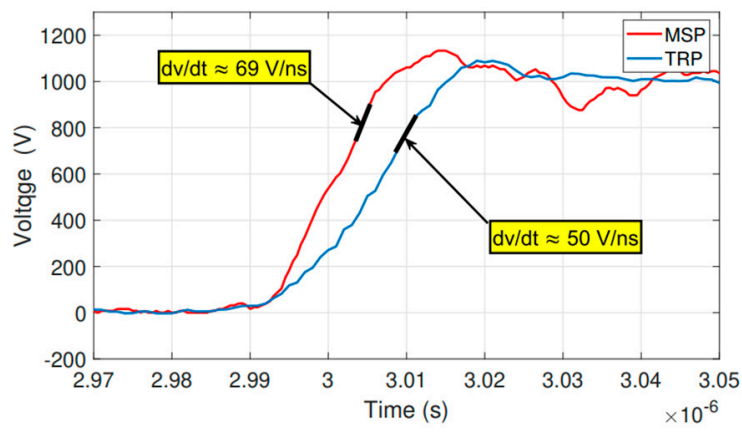

Figure 18. Measured $d v / d t$ for TRP and MSPs.

As can be seen, when the proposed MSP is applied for series-connected SiC-MOSFETs, it can mitigate voltage-balancing problems and also improve the switching speed when compared to the classical planar packaging. However, to explore the MSP at its full potential, thermal aspects have to be taken into account. 


\section{Thermal Management Considerations}

The MSP introduces nonhomogeneous propagation paths for the heat flux from each device to ambient. The addition of several dielectric layers, along with the number of steps, brings an increase in the junction-to-ambient thermal resistance, which produces an increase in junction temperature $T_{j}$ for the devices "above" with respect to the "bottom" device, the one located closer to the heat sink. This temperature increase is dependent on the heat flux and the characteristics of the additional dielectric layers. The lower the thermal resistance of the dielectric layer is, the lower the impact on the junction temperature will be. In addition, the lower the thermal resistance of the additional dielectric layer (s) is with respect to the remaining thermal resistance on the pathway of the heat, the lower the impact of the additional layers will be. A simple first order 1D thermal model can be developed to investigate this issue, as shown in Figure 19, where:

- $\mathrm{TjN}$ is the junction temperature of the device $\mathrm{N}$, "1" being the bottom device and " 2,3 and 4 " being the other "above" devices.

- Ta is the ambient temperature.

- Ps is the dissipation source in each device, representing the power losses, considered in this example as all equal.

- Rthjc is the junction-to-case thermal resistance (mainly the die itself and the die attach).

- Rthcs is the case-to-sink thermal resistance (mainly the dielectric layers).

- Rthsa is the heatsink thermal resistance (mainly the heat sink, including thermal grease).

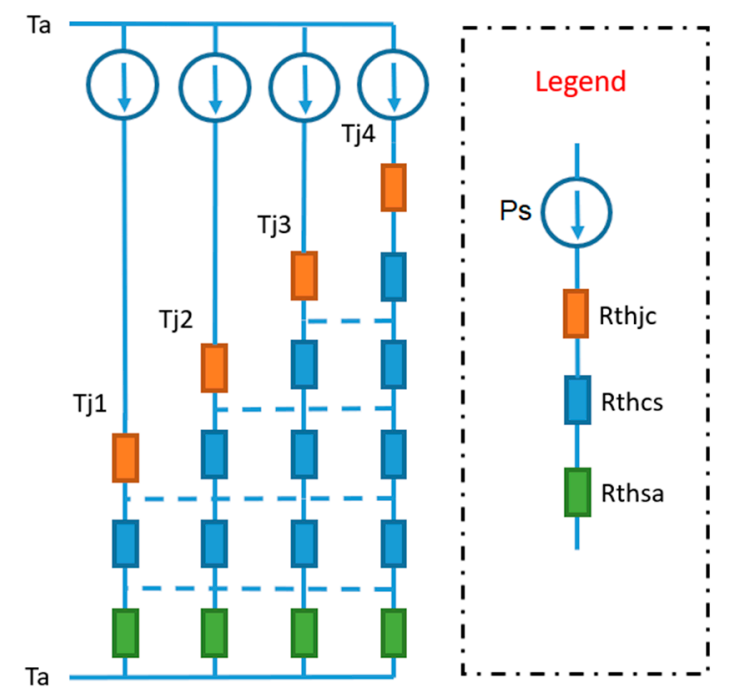

Figure 19. MSP thermal resistance $1 \mathrm{D}$ model.

Based on the equivalent circuit presented in Figure 19, the junction temperatures of the devices 2, 3, and 4 increase with respect to device 1. In Figure 20, a graph plots the impact of the thermal conductivity of the dielectric layer and its impact over junction temperature rise in MSP module. Some values used to calculate the junction temperature increase among the series-connected devices are based on the datasheet of the device used in the experiments, which leads to $R_{\text {thjc }}$ of $0.1 /{ }^{\circ} \mathrm{C}$ and a cross-section through the dielectric layer of $17 \times 14 \mathrm{~mm}^{2}$. The thickness of the dielectric material is considered constant and equal to $300 \mu \mathrm{m}$. It is also supposed that $\mathrm{T}_{\mathrm{a}}=25^{\circ} \mathrm{C}$, and the maximum acceptable junction temperature $\mathrm{T}_{\text {jmax }}$ is equal to $125^{\circ} \mathrm{C}$. Three dielectric materials are analyzed in Figure 20. A heat flux of $60 \mathrm{~W}$ is considered in the present analysis.

As can be seen in Figure 20a, the temperature increase among the devices is drastically dependent on the thermal conductivity of the dielectric material $\left(\mathrm{K}_{\mathrm{T}}\right)$. Considering a heat flux $\mathrm{P}_{\mathrm{s}}$ of $60 \mathrm{~W}$ and a dielectric composed by the FR4 material, the junction temperature distribution over the four power 
devices is unacceptable. A utopian $\mathrm{R}_{\text {thsa }} \approx-15.5 /{ }^{\circ} \mathrm{C}$ would be needed to keep the temperature among the devices below $110^{\circ} \mathrm{C}$. This is due to the very low thermal conductivity of FR4, i.e., $\mathrm{K}_{\mathrm{T}} \approx 0.3 \mathrm{~W} / \mathrm{mK}$. However, if other dielectric materials with better thermal resistance are used, such as $\mathrm{AlN}$ and $\mathrm{Al}_{2} \mathrm{O}_{3}$, the junction temperature distribution over the four power devices can be drastically reduced. As shown in Figure $20 \mathrm{~b}$, which is a zoom of Figure $20 \mathrm{a}$, considering $\mathrm{P}_{\mathrm{s}}$ equal to $60 \mathrm{~W}$, a $\mathrm{R}_{\text {thsa }}$ equal to $1.27 /{ }^{\circ} \mathrm{C}$ per device for planar design, and $\mathrm{Tj}=110^{\circ} \mathrm{C}$ for $\mathrm{Al}_{2} \mathrm{O}_{3}$ dielectric layers $\left(\mathrm{K}_{\mathrm{T}} \approx 25 \mathrm{~W} / \mathrm{mK}\right)$, the impact on $\mathrm{T}_{\mathrm{J}}$ is limited, with the temperature rise up to $10^{\circ} \mathrm{C}$. In the same way, for $300 \mu \mathrm{m}$ AlN dielectric layers $\left(\mathrm{K}_{\mathrm{T}} \approx 220 \mathrm{~W} / \mathrm{mK}\right)$ the impact on $\mathrm{Tj} 4$ is even more limited to $1{ }^{\circ} \mathrm{C}$. Taking into account the impact of a $\mathrm{T}_{\mathrm{j}}$ rise on device power losses, the resulting total temperature increase is up to $15^{\circ} \mathrm{C}$ for $\mathrm{Al}_{2} \mathrm{O}_{3}$ dielectric layers and $2.7^{\circ} \mathrm{C}$ for AlN dielectric materials.

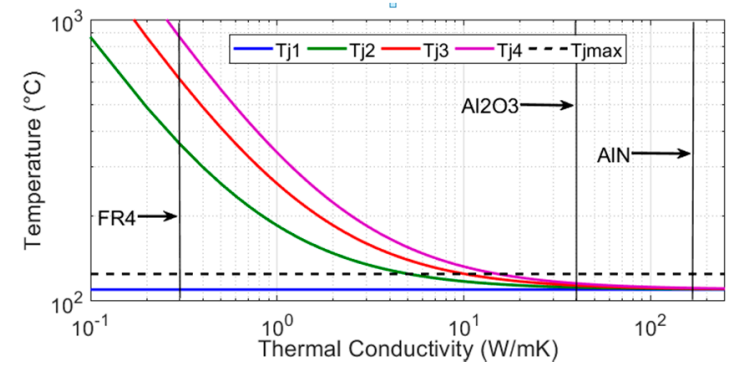

(a)

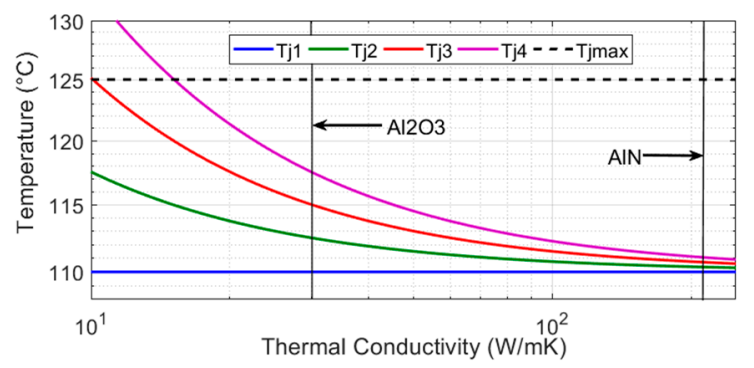

(b)

Figure 20. Junction temperature increase among the series-connected devices as a function of the thermal conductivity (a) and its zoomed view (b) for $\mathrm{P}_{\mathrm{s}}=60 \mathrm{~W}, \mathrm{~T}_{\mathrm{j}}=110{ }^{\circ} \mathrm{C}, \mathrm{T}_{\mathrm{a}}=25^{\circ} \mathrm{C}$, and $\mathrm{R}_{\text {thjc }}=0.1 /{ }^{\circ} \mathrm{C}$.

It is important to note that these results are highly dependent on heat flux and heat sink design. However, this brief analysis shows that if the additional dielectric layers have small thermal resistances with respect to the other thermal resistance on the path of the heat flux, then the MSP has a limited impact on the distribution of the junction temperatures $T_{j}$ of the devices implemented on each step of the power module. Neglecting the impact of junction temperature over component losses, if each additional dielectric layer introduces a thermal resistance $\mathrm{X} \%$ of the total thermal resistance from $T_{j}$ to $T_{a}$, then the impact on $T_{j}$ rise per step is limited to $X \%$. This would have a very limited impact on voltage sharing, as illustrated on Figure 12. If the junction temperature rise exceeds 5 to $10 \%$, the impact on component losses could be taken into account to verify that the final junction temperature rise for each component implemented in the MSP remains below the maximum junction temperature.

\section{Conclusions}

This paper proposes a new package concept to reduce the voltage unbalancing of SiC-MOSFETs in series connections. In a first step, the basics and the concept are explained using mathematical analysis. The package concept was compared to the traditional 2D planar solution in terms of voltage unbalance across the series-connected devices and $d v / d t$ behavior on the middle point of the switching cell. Then, to validate the interest of the new package, transient simulations using LTSpice software are provided as well as a comparison with a reference case. This first step validates the interest of the proposed package scheme according to voltage unbalancing and switching speed. Thereafter, experimental results are provided with comparable switching conditions: a bus voltage of $1 \mathrm{kV}$ and load current of $20 \mathrm{~A}$. The experimental results are in accordance with the simulation ones. The present work focuses on the benefits of the package concept with respect to switching speed and voltage balancing. According to the brief sensitive analysis and thermal investigations, the MSP seems realistic from a thermal point of view and for discrepancies between each die. Thermal and EMI aspects will be studied in more detail in future works.

Author Contributions: Conceptualization, J.-C.C., L.F.S.A., and P.L.; validation, L.F.S.A. and B.S.; formal analysis, L.F.S.A.; investigation, L.F.S.A., P.L., and P.-O.J.; writing—original draft preparation, L.F.S.A. writing-review 
and editing, P.L. and J.-C.C.; supervision, P.L., P.-O.J., and B.S. All authors have read and agreed to the published version of the manuscript.

Funding: This research has been supported by CNRS, Grenoble-INP, and UGA public institutions.

Conflicts of Interest: The authors declare no conflict of interest.

\section{References}

1. Wang, J.; Zhao, T.; Li, J.; Huang, A.Q.; Callanan, R.; Husna, F.; Agarwal, A. Characterization, Modeling, and Application of 10-kV SiC MOSFET. IEEE Trans. Electron. Devices 2008, 55, 1798-1806. [CrossRef]

2. Alves, L.F.S.; Gomes, R.C.M.; Lefranc, P.; Pegado, R.D.A.; Jeannin, P.-O.; Luciano, B.A.; Rocha, F.V. SIC power devices in power electronics: An overview. In Proceedings of the 2017 Brazilian Power Electronics Conference (COBEP), Juiz de Fora, Brazil, 19-22 November 2017; pp. 1-8.

3. Luciano, F.S.A.; Van-Sang, N.; Pierre, L.; Benoît, S.; Pierre-Olivier, J.; Alexis, D.; Jean-Christophe, C. Gate Driver Architectures Impacts on Voltage Balancing of SiC MOSFETs in Series Connection. In Proceedings of the 2018 20th European Conference on Power Electronics and Applications (EPE'18 ECCE Europe), Riga, Latvia, 17-21 September 2018; pp. P.1-P.9.

4. Mainali, K.; Tripathi, A.; Madhusoodhanan, S.; Kadavelugu, A.; Patel, D.; Hazra, S.; Hatua, K.; Bhattacharya, S. A Transformerless Intelligent Power Substation: A three-phase SST enabled by a 15-kV SiC IGBT. IEEE Power Electron. Mag. 2015, 2, 31-43. [CrossRef]

5. Eni, E.-P.; Kerekes, T.; Uhrenfeldt, C.; Teodorescu, R.; Munk-Nielsen, S.; Emanuel-Petre, E. Design of low impedance busbar for $10 \mathrm{kV}, 100 \mathrm{~A} 4 \mathrm{H}-\mathrm{SiC}$ MOSFET short-circuit tester using axial capacitors. In Proceedings of the 2015 IEEE 6th International Symposium on Power Electronics for Distributed Generation Systems (PEDG), Aachen, Germany, 22-25 June 2015; pp. 1-5.

6. Bolotnikov, A.; Losee, P.; Permuy, A.; Dunne, G.; Kennerly, S.; Rowden, B.; Nasadoski, J.; Todorovic, M.H.; Raju, R.; Tao, F.; et al. Overview of $1.2 \mathrm{kV}-2.2 \mathrm{kV}$ SiC MOSFETs targeted for industrial power conversion applications. In Proceedings of the 2015 IEEE Applied Power Electronics Conference and Exposition (APEC), Charlotte, NC, USA, 15-19 March 2015; pp. 2445-2452.

7. Withanage, R.; Shammas, N. Series connection of insulated gate bipolar transistors (IGBTs). IEEE Trans. Power Electron. 2012, 27, 2204-2212. [CrossRef]

8. Jørgensen, A.B.; Christensen, N.; Dalal, D.N.; Sønderskov, S.D.; Beczkowski, S.; Uhrenfeldt, C.; Munk-Nielsen, S. Reduction of parasitic capacitance in $10 \mathrm{kV}$ SiC MOSFET power modules using 3D FEM. In Proceedings of the 2017 19th European Conference on Power Electronics and Applications (EPE'17 ECCE Europe), Warsaw, Poland, 11-14 September 2017; pp. P.1-P.8.

9. Lim, T.C.; Williams, B.W.; Finney, S.J.; Palmer, P.R. Series-connected IGBTs using active voltage control technique. IEEE Trans. Power Electron. 2013, 28, 4083-4103. [CrossRef]

10. Finney, S.; Williams, B.; Green, T.C. RCD snubber revisited. IEEE Trans. Ind. Appl. 1996, 32, 155-160. [CrossRef]

11. Ji, S.; Lü, T.; Zhao, Z.; Yu, H.; Yuan, L. Series-connected HV-IGBTs using active voltage balancing control with status feedback circuit. IEEE Trans. Power Electron. 2015, 30, 4165-4174. [CrossRef]

12. Grbovic, P.J. High-voltage auxiliary power supply using series-connected MOSFETs and floating self-driving technique. IEEE Trans. Ind. Electron. 2009, 56, 1446-1455. [CrossRef]

13. Alves, L.F.S.; Lefranc, P.; Jeannin, P.-O.; Sarrazin, B.; Crebier, J.-C. Multi-Step Packaging Concept for Series-Connected SiC MOSFETs. In Proceedings of the 2019 21st European Conference on Power Electronics and Applications (EPE ‘19 ECCE Europe), Genova, Italy, 3-5 September 2019; pp. P.1-P.10.

14. Alves, L.F.S.; Lefranc, P.; Jeannin, P.-O.; Sarrazin, B. Review on SiC-MOSFET devices and associated gate drivers. In Proceedings of the 2018 IEEE International Conference on Industrial Technology (ICIT), Lyon, France, 20-22 February 2018; pp. 824-829.

15. Guo, S.; Zhang, L.; Lei, Y.; Li, X.; Yu, W.; Huang, A.Q. Design and application of a 1200V ultra-fast integrated Silicon Carbide MOSFET module. In Proceedings of the 2016 IEEE Applied Power Electronics Conference and Exposition (APEC), Long Beach, CA, USA, 20-24 March 2016; pp. 2063-2070.

16. Klein, K.; Hoene, E.; Reiner, R.; Quay, R. Study on Packaging and Driver Integration with GaN Switches for Fast Switching. In Proceedings of the CIPS 2016 9th International Conference on Integrated Power Electronics Systems, Nuremberg, Germany, 8-10 March 2016; pp. 1-6. 
17. Kreutzer, O.; Eckardt, B.; Maerz, M. Optimum gate driver design to reach SiC-MOSFET's full potential-speeding up to $200 \mathrm{kV} / \mathrm{us}$. In Proceedings of the Wide Bandgap Power Devices and Applications (WiPDA), 2015 IEEE 3rd Workshop on, Blacksburg, VA, USA, 2-4 November 2015; pp. 41-46.

18. Dalal, D.N.; Christensen, N.; Jorgensen, A.B.; Jorgensen, J.K.; Beczkowski, S.; MunkNielsen, S.; Uhrenfeldt, C. Impact of power module parasitic capacitances on medium voltage sic mosfets switching transients. IEEE J. Emerg. Sel. Top. Power Electron. 2019, 8, 298-310. [CrossRef]

19. James, A. Influence of device parameters spread on current distribution of paralleled silicon carbide mosfets. J. Power Electron. 2019, 19, 1054-1067.

(C) 2020 by the authors. Licensee MDPI, Basel, Switzerland. This article is an open access article distributed under the terms and conditions of the Creative Commons Attribution (CC BY) license (http://creativecommons.org/licenses/by/4.0/). 